\title{
From Submission to Acceptance: An Assessment of the Performance of the Nigerian Journal of Animal Production.
}

\author{
E.A Awojobi \\ College Library, College of Agricultural Sciences, Olabisi Onabanjo University, Yewa \\ Campus, \\ P.M.B. 0012, Ayetoro, Ogun State, Nigeria. \\ Corresponding author E-mail: esbog.awoj@yahoo.com
}

\begin{abstract}
Duration of time to acceptance of articles for publication in the Nigerian Journal of Animal Production (NJAP) was examined in this study. A total of 448 articles in 12 volumes published between 1995 and 2006 were used for the study Results showed that mean number of days to acceptance was 442.76 days, with a range of 348.09 days in 2005 to 620.86 days in 2002. Articles on livestock diseases took the longest time of 522.15 days from submission to acceptance and this was significantly $(P<0.05)$ longer than the number of days for articles in breeding and genetics (378.47days), livestock economics and extension (378.23days) and fisheries and wild life (316.55days). Based on the species of animal used for experimentation, mean number of days to acceptance was longest $(P<0.05)$ for articles on cattle (536.04days) which was significantly higher $(P<0.05)$ than for goat $(366.25$ days) and fish (295.45days). A significant $(P<0.05)$ positive correlation $(r=0.109)$ was observed between days to acceptance and the distance between author and editor. This study alluded to the existence of other factors yet to be uncovered that can be militating against quick acceptance of articles in NJAP and ofters suggestions for improvement.
\end{abstract}

Keywords: Performance evaluation, Acceptance, Nigerian Journal of Animal Production

\section{Introduction}

Journals are the source of up-to-date information for scientific research and constitute the most important form of publication in the field of science and technology (Nwagha, 1980). In fact journals account for between 70 and $82 \%$ of literature used (Earle and Vickery, 1969) it therefore gladdens the heart of scientists to be involved in communicating their findings through this medium. Besides, it is an avenue for establishing the reputation of scientists, inspiring new directions of research and it also creates opportunity for collaboration. According to Nwagha (1980) the consequences of not communicating through journals is serious. This includes duplication of work, waste of money and portrayal of ignorance of relevant facts. Another serious penalty is captured by the
Popular saying in academic circles, "publish or perish". The advancement of an academic staff, unlike other staff, depends largely if not almost entirely on his research output (Ogunkoya, 2002).

However, journal articles pass through review process. The extensiveness or complexity of the review process will dictate the amount of time before an article is published. In a survey study by Brackbill and Korten (1970), the utmost fear of researchers was reported to be the long review time of their manuscripts. This fear is still very much with us today. This paper examines the average time taken to review articles submitted to the Nigerian Journal of Animal Production over a period of twelve years (19952006). Time taken to review articles were also assessed along areas of specialization 
and species of animal used and some features of the articles were also evaluated as correlates of time to asses their influence on duration of time from submission to acceptance of an article for publication.

\section{Materials and Methods}

A total of 448 articles were evaluated in this study. These were articles published in the Nigerian Journal of Animal Production from 1995-2006 i.e. vol 22 -33. Information were obtained from each article on: date submitted (month and year), date accepted (month and year), number of authors, area of specialization of article, species of animal used for experimentation, number of pages, tables, figures and references, distance $(\mathrm{km})$ from author to editorin-chief (the address of the first author was used in calculating the distance).।

Results and Discussion

Table 1: Frequency distribution of articles by month of submission

\begin{tabular}{lll}
\hline Month & Frequency & Percent \\
\hline Not indicated & 5 & 1.1 \\
January & 24 & 5.4 \\
February & 36 & 8.0 \\
March & 78 & 17.4 \\
April & 32 & 7.1 \\
May & 42 & 9.4 \\
June & 22 & 4.9 \\
July & 49 & 10.9 \\
August & 35 & 7.8 \\
September & 44 & 9.8 \\
October & 28 & 6.3 \\
November & 29 & 6.5 \\
December & 24 & 5.4 \\
\hline Total & 448 & 100.0 \\
\hline
\end{tabular}

Summarization of data was done using simple descriptive statistics, days to acceptance between years, discipline and species of animals used for experimentation was carried out using one way Analysis of Variance. Significantly different means were separated using Duncan's multiple range test (Duncan,1955). All statistical analysis were done using the Statistical Package for the Social Sciences (SPSS).

Table 1 shows the distribution of articles according to the month they were received. This result demonstrated that March was the peak period for the submission of articles to the Nigerian Journal of animal Production (NJAP). A total of 78 articles out of 448 representing 17.42 were submitted in March. Since the Nigerian society of Animal Production (NSAP) holds her annual conference in the month of March every year, participants probably used this opportunity to submit articles to the editor-in-chief by hand. The result of the distribution of articles by the month in which they are accepted for publication is presented in Table 2.

Table 2: Frequency distribution of articles by month of acceptance.

\begin{tabular}{lll}
\hline Month & Frequency & Percent \\
\hline Not indicated & 4 & 0.9 \\
January & 27 & 6.0 \\
February & 15 & 3.3 \\
March & 40 & 8.9 \\
April & 28 & 6.3 \\
May & 46 & 10.3 \\
June & 26 & 5.8 \\
July & 41 & 9.2 \\
August & 43 & 9.6 \\
September & 51 & 11.4 \\
October & 43 & 9.6 \\
November & 54 & 12.1 \\
December & 30 & 6.7 \\
\hline Total & 448 & 100.0 \\
\hline
\end{tabular}


Table 3: Distribution of articles by range of days to acceptance

\begin{tabular}{lll}
\hline Days & Frequency & Percent \\
\hline Not indicated & 11 & 2.5 \\
$0-99$ & 9 & 2.0 \\
$100-199$ & 58 & 12.9 \\
$200-299$ & 73 & 16.3 \\
$300-399$ & 97 & 21.7 \\
$400-499$ & 60 & 13.4 \\
$500-599$ & 48 & 10.7 \\
$600-699$ & 26 & 5.8 \\
$700-799$ & 23 & 5.1 \\
$800-899$ & 17 & 3.8 \\
$900-999$ & 3 & 0.7 \\
$1000-1199$ & 20 & 4.5 \\
$2000-2999$ & 3 & 0.7 \\
\hline Total & 448 & 100.0 \\
\hline
\end{tabular}

Peak periods are in the months of September and November with $11.4 \%$ and $12.1 \%$ accepted respectively. The editorial office must definitely be preparing to go to press to get NJAP ready for the NSAP conference in March. Suffice to say that annual appraisals for promotion in higher institutions takes place around this period, the editorial office many therefore be under pressure from authors. Table 3 shows the distribution of articles by the range of the number of days from submission to acceptance, majority of the articles 97 $(21.7 \%)$ were accepted for publication in 300-399days, after submission (approximately one year) and as much as $20(4.5 \%)$ articles were accepted after about three years (1000-1199 days) of submission. This result agrees with the Survey of Brackbill and Korten (1970) who reported that the utmost fears of authors is the time duration taken before their articles are reviewed.
Table 4: Days to acceptance in No 1 and 2

\begin{tabular}{lll}
\hline Number & N & $\begin{array}{l}\text { Days to } \\
\text { acceptances }\end{array}$ \\
\hline 1 & 253 & 430.20 \\
2 & 195 & 459.06 \\
\hline Total & 448 & SEM:16.42 \\
\hline
\end{tabular}

The NJAP is usually published as two numbers in one volume. Table 4 shows that $56.5 \%$ of the articles appeared in number 2 while $43.5 \%$ appeared in number 1. Mean number of days of acceptance was 430.20 and 459.06 for No 1 and 2 respectively. Though the number of days was slightly longer for No.2 than No1, it was statistically non-significant $(\mathrm{P}>0.05)$. Table 5 shows that mean number of days to acceptance for all volumes of the NJAP published between 1995 and 2006. Values ranged from 346.09 days in vol 32 (2005) to 620.86 days in Vol. 29 (2002). Mean number of days to acceptance was significantly $(\mathrm{P}<0.05)$ longer in year 2002 than 2006, 2003, 1997, 1996, 2004, 1995, 2000, 1999, 1998 and 2005. Mean number of days to acceptance for year 2002 was only comparable $(\mathrm{P}>0.5)$ to that of 2001, while values for 2001, 2006 and 2003 are also comparable $(\mathrm{P}>0.05)$. Mean number of days to acceptance did not show any trend of improvement during the years under consideration. Mean number of days to acceptance according to discipline or area of specialization is presented in Table 6, values ranged from 316.55 days for articles in fishery and wildlife to 522.115 days for articles on livestock diseases. Mean number of days to acceptance was significantly $(\mathrm{P}<0.05)$ longer for articles on livestock diseases (522.15 days) than breeding and genetics (378.25 days) and fishery and wildlife 316.55 days). Mean number of days to acceptance is comparable $(\mathrm{P}>0.05)$ across all the other specializations. Since most 
articles on livestock diseases are likely to be reviewed by veterinarians, it is not unlikely that commitment to the review of articles coming from their professional journals will, lengthen the time taken to review articles from NJAP.

Results from Table 6 also showed that the highest number of publications come from non-ruminant nutrition (163, $36.4 \%$ ). This suggests the preponderance of a higher number of specialists in this area, but this does not translate to better efficiency in the number of days to accept articles published in this area. In fact in the core areas of animal production,

\begin{tabular}{|c|c|c|c|c|}
\hline Year & Volume & $\mathrm{N}$ & $\begin{array}{l}\text { D ays } \\
\text { acceptance }\end{array}$ & to \\
\hline 1995 & 22 & 37 & $396.76^{\mathrm{c}}$ & \\
\hline 1996 & 23 & 43 & $432.00^{\mathrm{c}}$ & \\
\hline 1997 & 24 & 37 & $432.78^{\mathrm{c}}$ & \\
\hline 1998 & 25 & 41 & $375.37^{\mathrm{c}}$ & \\
\hline 1999 & 26 & 25 & $389.24^{\mathrm{c}}$ & \\
\hline 2000 & 27 & 24 & $390.79^{\mathrm{c}}$ & \\
\hline 2001 & 28 & 40 & 586.98 ab & \\
\hline 2002 & 29 & 42 & $620.86^{a}$ & \\
\hline 2003 & 30 & 38 & 446.24 bc & \\
\hline 2004 & 31 & 39 & $405.64^{c}$ & \\
\hline 2005 & 32 & 44 & $346.09^{\mathrm{c}}$ & \\
\hline 2006 & 33 & 38 & $448.13^{b c}$ & \\
\hline Total & & 448 & SEM: 73.12 & \\
\hline
\end{tabular}

articles in breeding and genetics had the least number of days to acceptance (378.23 days), yet judging by the number of articles from this field $(55,12.3 \%)$ it is one of the areas with the least number of specialists. Table 7 shows the mean number of days to acceptance according to the species of animal used for experimentation. Expectedly majority of the articles are on poultry $(159,35.5 \%)$ and this agrees with the finding of Adewole (1991) in his article on some characteristics of articles published in the
Nigerian Journal of Animal Production. The least number of articles are on fish, this is again understandable since it does not come under livestock species per se. Mean number of days to acceptance is shortest in articles on fish (295.45 days) and this value is significantly $(\mathrm{P}<0.05)$ lower than that of cattle (536.04 days), sheep (477.55 days) and poultry (461.75 days), and comparable to that of swine (409.52 days), rabbit (398.13 days) and goat (366.25 days).From this result, it is clear that a preponderance

Table 6: Days to acceptance according to specialization

\begin{tabular}{|c|c|c|}
\hline Specialization & $\mathrm{N}$ & $\begin{array}{l}\text { Days to } \\
\text { acceptance }\end{array}$ \\
\hline Not indicated & 3 & $393.67 \mathrm{ab}$ \\
\hline Breeding and Genetics & 55 & $378.47 b$ \\
\hline Non-ruminant Nutrition & 163 & $451.93 \mathrm{ab}$ \\
\hline Ruminant Nutrition & 69 & $461.43 \mathrm{ab}$ \\
\hline Livestock Products & 35 & $409.51 \mathrm{ab}$ \\
\hline Livestock Eco/Ext. & 26 & $378.23 b$ \\
\hline Livestock Diseases & 40 & $522.15 \mathrm{a}$ \\
\hline Management & 18 & $467.28 \mathrm{ab}$ \\
\hline Fishery/Wildlife & 11 & $316.55 b$ \\
\hline $\begin{array}{l}\text { Physiology/Animal } \\
\text { Behaviour }\end{array}$ & 28 & $496.82 \mathrm{ab}$ \\
\hline Total & 488 & $\begin{array}{l}\text { SEM: } \\
71.52\end{array}$ \\
\hline
\end{tabular}

Table 7: Days of acceptance according to the species used for experimentation.

\begin{tabular}{lll}
\hline Species & $\mathrm{N}$ & $\begin{array}{l}\text { Days to } \\
\text { acceptance }\end{array}$ \\
\hline Not indicated & 68 & 437.10 \\
Poultry & 159 & 461.75 \\
Sheep & 33 & 477.55 \\
Rabbit & 46 & 398.13 \\
Swine & 29 & 409.52 \\
Goat & 51 & 366.25 \\
Cattle & 51 & 536.04 \\
Fish & 11 & 295.45 \\
\hline Total & 448 & SEM: 23 \\
\hline
\end{tabular}


poultry (461.75 days), and comparable to that of swine (409.52 days), rabbit (398.13 days) and goat (366.25 days).From this result, it is clear that a preponderance of authors conducting research on a particular species did not equally guarantee shorter number of days to acceptance. An attempt was also made to evaluate the possible effect of some characteristics of the articles on the number of days to acceptance. Results however showed that there is no significant $(\mathrm{P}>0.05)$ correlation between the number of days to acceptance and such characteristics of the article like number of references, number of figures, number of pages, number of authors and number of tables. However, results showed a significantly $(\mathrm{P}<0.05)$ positive correlation $(\mathrm{r}=0.109)$ between the number of days to acceptance and the distance $(\mathrm{km})$ between the author and editor-in- chief. This finding does not explain the observations on the performance across the years as mean distance from author to editor in 2001 was $303.55 \mathrm{~km}$ as against $454.82 \mathrm{~km}$ in 1996 , yet mean number of days to acceptance was significantly $(\mathrm{P}<0.05)$ longer in 2001 than in 1996. This therefore suggests that there is more to delay in the time spent on the review of articles than distance from author to editor. Such other factors described by Lay (1987) as temporal factors in the review process includes: reviewers days to review, editors days to review, number who previewed manuscript, authors days to revise, clarity of manuscript, appropriateness to journal standard/format among others.

\section{Conclusion}

This study has demonstrated that articles take a fairly long period before acceptance in the NJAP. The journal has equally not shown a consistent pattern of improvement in the days to acceptance of articles in the years considered. The distance between authors and the editorial office has been indicated as one of the sources of delay in acceptance. The journal will do well to embrace versatility of the internet through on-line submission of articles in the addition to the receiving articles by post. It is interesting to note from this study that an abundance of researchers in a particular area does not guarantee shorter days to acceptance of article. It is therefore desirable to look into the records of the editorial office for an in depth study of temporal factors in the review process as described by Lay (1987). This should be with the objective of blocking the loop holes and reducing days to acceptance and publication delay.

\section{References}

Adewole, S. (1991). Some characteristics of articles published in the Nigerian Journal of Animal Production. Nig. J. Anim. Prod 18:27-33

Brackbill, Y, and Korten, F. (1970). Journal reviewing practices: Authors and APA members suggestions for revision. Psychologists, 25:937-940.

Earle, P. and Vickery, B. (1969). Social science literature use in the UK as indicated by citations. Journal of documentation 25: 123-141.

Lay, C.H. (1987). Publication delay: An analysis of journal days reviewer days and author days to revision. Canad. J. Behav. Scil Rev. Canad. Sci. Comp. 19 (3): 324-331.

Nwagha, G.K.N (1980): Barriers to the accessibility of scientific journals in Nigeria. Int. Libr. Rev 12: 201207.

Ogunkoya, L. (2002): in defense of ASUU. The Comment, Sunday, May 8, 2002. P.37 